\title{
A human Dravet syndrome model from patient induced pluripotent stem cells
}

\author{
Norimichi Higurashi ${ }^{1,2,3}$, Taku Uchida ${ }^{2}$, Christoph Lossin ${ }^{4}$, Yoshio Misumi ${ }^{5}$, Yohei Okada ${ }^{6,7}$, Wado Akamatsu ${ }^{6}$, \\ Yoichi Imaizumi ${ }^{6}$, Bo Zhang ${ }^{8}$, Kazuki Nabeshima ${ }^{9}$, Masayuki X Mori ${ }^{10}$, Shutaro Katsurabayashi ${ }^{11}$, \\ Yukiyoshi Shirasaka ${ }^{12}$, Hideyuki Okano $0^{6^{*}}$ and Shinichi Hirose ${ }^{1,2^{*}}$
}

\begin{abstract}
Background: Dravet syndrome is a devastating infantile-onset epilepsy syndrome with cognitive deficits and autistic traits caused by genetic alterations in SCN1A gene encoding the a-subunit of the voltage-gated sodium channel $\mathrm{Na}_{v}$ 1.1. Disease modeling using patient-derived induced pluripotent stem cells (iPSCs) can be a powerful tool to reproduce this syndrome's human pathology. However, no such effort has been reported to date. We here report a cellular model for DS that utilizes patient-derived iPSCS.

Results: We generated iPSCs from a Dravet syndrome patient with a c.4933C > T substitution in SCN1A, which is predicted to result in truncation in the fourth homologous domain of the protein (p.R1645*). Neurons derived from these iPSCs were primarily GABAergic (>50\%), although glutamatergic neurons were observed as a minor population $(<1 \%)$. Current-clamp analyses revealed significant impairment in action potential generation when strong depolarizing currents were injected.

Conclusions: Our results indicate a functional decline in Dravet neurons, especially in the GABAergic subtype, which supports previous findings in murine disease models, where loss-of-function in GABAergic inhibition appears to be a main driver in epileptogenesis. Our data indicate that patient-derived iPSCS may serve as a new and powerful research platform for genetic disorders, including the epilepsies.
\end{abstract}

Keywords: Induced pluripotent stem cells, Disease modeling, Dravet syndrome, SCN1A, Nav1.1, Epileptogenesis, Action potential, Gamma aminobutyric acid

\section{Background}

Dravet syndrome (DS) is an infantile-onset epileptic encephalopathy that develops in a previously normal infant [1]. Seizures are refractory to all currently available forms of treatment; severe neuropsychiatric disabilities include cognitive deficits and autism-spectrum behaviors, and approximately $10-20 \%$ of the afflicted children do not survive $[2,3]$. Clearly, new and improved treatment modalities are needed, but their development hinges on research platforms that faithfully reproduce the human pathology.

\footnotetext{
* Correspondences: hidokano@a2.keio.jp; hirose@fukuoka-u.ac.jp

${ }^{6}$ Department of Physiology, Keio University School of Medicine,

35 Shinanomachi, Shinjuku-ku, Tokyo 160-8582, Japan

'Department of Pediatrics, School of Medicine, Fukuoka University, 45-1,

7-chome, Nanakuma, Jonan-ku, Fukuoka 814-0180, Japan

Full list of author information is available at the end of the article
}

Defects in the SCN1A gene, which encodes the $\alpha$ subunit of the voltage-gated sodium channel $\mathrm{Na}_{\mathrm{v}} 1.1$, are seen in $70-80 \%$ of patients with DS, and approximately $50 \%$ of these defects truncate the $\mathrm{Na}_{\mathrm{v}} 1.1$ protein prematurely $[4,5]$. Various approaches have been used to describe and characterize the condition, most notably heterologous expression of $\mathrm{Na}_{\mathrm{v}} 1.1$ mutants [6,7] and, more recently, the development of DS mouse models, which are based on heterozygotes of an Scn1a knock-out/knock-in [8,9], or cell-type specific conditional knock-out $[10,11]$. These efforts have revealed the pathogenic mechanism for DS likely involves $\mathrm{Na}_{\mathrm{v}} 1.1$ haploinsufficiency [11-14]. Additionally, in the rodent forebrain, $\mathrm{Na}_{\mathrm{v}} 1.1$ is predominantly expressed in GABAergic interneurons [15], especially in the axon initial segment of a parvalbumin (PV)-positive subgroup [9], where $\mathrm{Na}_{\mathrm{v}} 1.1$ has been suggested to directly influence action potential generation and thereby exert

\section{Biomed Central}


excitation control over downstream pyramidal neurons [16]. Impaired inhibition through disruption of this suppression by forebrain GABAergic neurons may be the main pathogenic mechanism underlying the seizure susceptibility of DS $[8-10,17]$. A recent study has indicated that autismrelated behaviors in $\mathrm{Scn} 1 \mathrm{a}^{+/-}$mice result from the impaired GABAergic neurotransmission [11]. The full spectrum of factors contributing to the phenotype, however, is likely more complex with additional, so far unidentified components modifying the presentation.

Various neurological disease models have been developed using patient-derived iPSCs [18-23], but to date, no such effort has been reported toward epilepsy. Due to the early onset of the disorder and the wealth of knowledge on the associated genetic defects, DS is a highly suitable candidate for iPSC technology. We here report the first successful development of an iPSC-based DS model incorporating a nonsense mutation in SCN1A, and we show how neurons of this model have abnormal electrophysiological responses.

\section{Results}

Patient demographics and history

The tissue donor was a female patient who was born in an uneventful delivery of dizygotic twins at 38 weeks of gestation. Her birth weight was $2850 \mathrm{~g}$. There were no complications during the perinatal and early postnatal period. However, at 6 months of age, she experienced her first seizure with loss of consciousness. At 7 months of age, generalized tonic-clonic seizures began, often prolonged, and induced by fever or hot baths. Despite anticonvulsant therapy, she later developed facial myoclonia and focal seizures, and obtundation status [24]. Generalized polyspikes-waves were identified in interictal electroencephalography. At the age of 21, direct sequencing of blood leukocyte-extracted genomic DNA revealed an SCN1A point mutation, c.4933C>T [GenBank: NM_001165963.1] (Figure 1A) as first reported by Fukuma and co-workers [25], which is expected to prematurely truncate the $\mathrm{Na}_{\mathrm{v}} 1.1$ protein in the fourth homologous domain (p.R1645*, Additional file 1) [GenPept: NP_001159435.1]. By 29 years

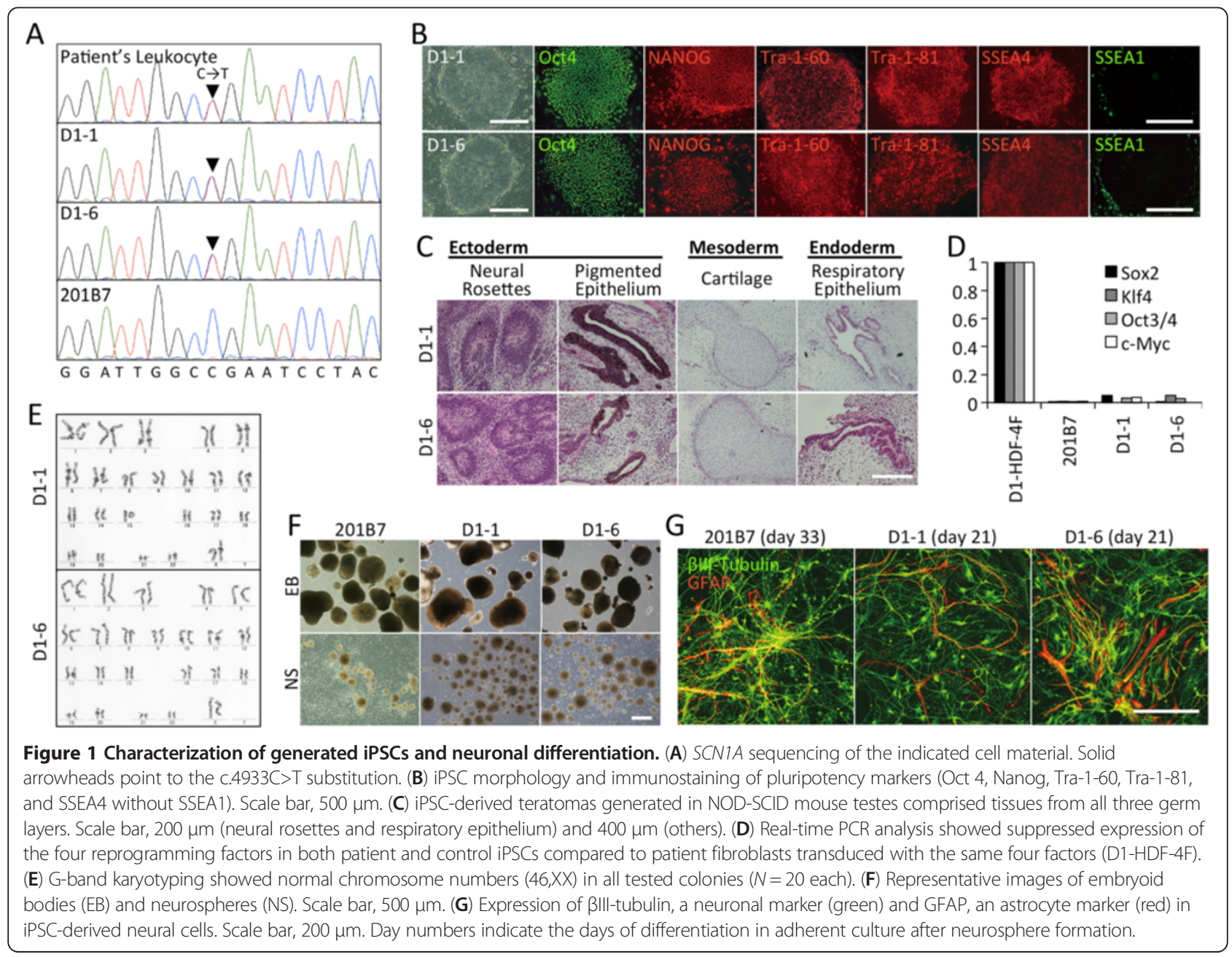


of age, when a skin biopsy was performed, she had developed profound intellectual disability as well as ataxia. At that time, she had 7-8 nocturnal generalized tonicclonic seizures a month and obtundation status once every 2-3 months.

\section{Characterization of the generated iPSCs}

Two lines of patient-derived iPSCs, D1-1 and D1-6, were established from skin fibroblasts obtained from the biopsy specimen. Control experiments used the iPSC line, 201B7, which was developed from the facial skin of a 36-year-old Caucasian female as reported previously [26]. All iPSC colonies had the typical human embryonic stem cell morphology with tightly-packed cells, a clear border, and a round shape (Figure 1B). Expression of pluripotency markers was confirmed (Figure 1B); additional analysis showed that the resulting teratomas consisted of tridermic tissues (Figure 1C), which supports the iPSCs' undifferentiated state and pluripotency. Silencing of reprogramming transgenes, normal karyotype $(46, \mathrm{XX})$, and the presence of the $S C N 1 A$ c. $4933 C>\mathrm{T}$ variation were confirmed (Figure 1D, E, A, respectively). Direct sequencing of additional sodium channels genes, the closely related $S C N 2 A$ as well as the genes for subunits $\beta 1$ and $\beta 2$ (SCN1B and $S C N 2 B$ ) revealed wildtype status for all examined sequence regions (data not shown). During neural induction, all clones efficiently generated neurospheres (Figure 1F). In adherent cells differentiated from neurospheres, the expression of neuron and astrocyte markers was confirmed ( $\beta$ III-tubulin and GFAP, respectively - Figure 1G). Staining for CNPase, an oligodendrocyte marker was negative in all cell lines.

\section{$\mathrm{Na}_{\mathrm{v}}$ expression in iPSC-derived neurons}

To determine the expression levels for those voltagegated sodium channels, that predominate in the brain, we used real-time PCR targeting genes SCN1A, SCN2A (protein name: $\left.\mathrm{Na}_{\mathrm{v}} 1.2\right), S C N 3 A\left(\mathrm{Na}_{\mathrm{v}} 1.3\right)$, and $S C N 8 A$ $\left(\mathrm{Na}_{\mathrm{v}} 1.6\right)$ on iPSCs-derived neurons at 30 days of differentiation. In all cell lines, $S C N 2 A$ expression was highest, followed by $S C N 1 A, S C N 3 A$, and $S C N 8 A$ (Figure 2A and Additional file 2). When the expression levels were normalized to each other, we found that $S C N 1 A$ tended to be expressed higher in the patient neurons than in control neurons (Figure 2B). We furthermore confirmed that, in patient neurons, SCN1A mRNA translated from the mutated allele was present (Figure $2 \mathrm{C}$ ), which suggests that the mutated mRNA was able to escape nonsensemediated decay, possibly owing to the mutation locating to the last coding exon [27].

We next examined $\mathrm{Na}_{\mathrm{v}} 1.1$ expression at the protein level using a polyclonal antibody targeting the D1-D2 linker (Additional file 1). Among BIII-tubulin-positive cells, $\mathrm{Na}_{\mathrm{v}} 1.1$ immunostaining was identified in $59.0 \%$ or
$105 / 178$ in $201 \mathrm{~B} 7,52.1 \%$ or $139 / 267$ in D1- 1 , and $58.1 \%$ or $151 / 260$ in D1-6 neurons. $\mathrm{Na}_{\mathrm{v}} 1.1$-immunostaining was evident in cell bodies, dendrites, and axons (Figure 2D, E); the antibody's specificity was confirmed with epitope peptide pre-treatment (Additional file 3). Neurons with well-developed axons often displayed strong axonal $\mathrm{Na}_{\mathrm{v}} 1.1$ staining (Figure 2E). Intense expression of $\mathrm{Na}_{\mathrm{v}}$ channels (PAN- $\mathrm{Na}_{\mathrm{v}}$ ) in the axon initial segment became evident after several weeks of in vitro differentiation of neurospheres (Figure 2F, Additional file 4A). This spatial and temporal expression pattern has been suggested to be critical in action potential generation [28].

\section{Subtypes of $\mathrm{Na}_{\mathrm{v}}$ 1.1-positive neurons}

The majority of the $\mathrm{Na}_{\mathrm{v}} 1.1$-positive control and patientderived neurons were GABAergic in nature as established by GAD67 staining ( $58.3 \%$ or $260 / 446$ in $201 B 7$, Figure 2G; $54.8 \%$ or $292 / 533$ in D1-1; and $52.6 \%$ or $214 / 407$ in D1-6, Additional file 4B). We next examined $\mathrm{Na}_{\mathrm{v}} 1.1$ expression differences among the subtypes of GABAergic neurons based on co-expression of PV, calretinin, or somatostatin. In mouse brain, strong $\mathrm{Na}_{\mathrm{v}} 1.1$ expression has been shown in PV-positive interneurons, whereas somatostatin- and calretinin-positive neurons show none [29]. This study produced several calretinin-positive 201B7 control neurons that also stained for $\mathrm{Na}_{\mathrm{v}} 1.1$ after 33 days of differentiation ( $44.4 \%$ or $8 / 18$, Additional file $5 \mathrm{~A}$ ). Somatostatin-positive neurons, on the other hand, presented with either faint or negligible $\mathrm{Na}_{\mathrm{v}} 1.1$-staining in all cases $(N=10$ and 7 in 201B7 and D1-6 neurons, respectively - Additional file $5 \mathrm{~B})$. PV expression was not detectable, even after treatment with sonic-hedgehog (shh) [30] or purmorphamine (a shh-signaling agonist) [31] for ventralization, and/ or BMP4 [32] However, we did detect PV mRNA (Additional file 6) as well as mRNA for Nkx2.1, a medial ganglionic eminence neuron marker $[33,34]$ that is elevated by the ventralizing treatments (Additional file 7) $[35,36]$. Thus, while PV-neuron precursors were likely present, our culture conditions may have interfered with further maturation.

Although it was technically difficult to distinguish subtypes other than GABAergic amongst the $\mathrm{Na}_{\mathrm{v}} 1.1$ positive neurons, some were positive for VGlut1, a marker of glutamatergic neurons, as a minor population $(<1 \%)$, and on occasion, these neurons co-localized with $S C N 1 A$ Venus fluorescence (i.e. SCN1A expression, Figure $2 \mathrm{H}$ and Additional file 4C).

\section{SCN1A-reporter for electrophysiology}

To reliably identify $S C N 1 A$-expressing neurons for electrophysiological analyses, we generated a lentiviral reporter for $S C N 1 A$. The reporter contained $S C N 1 A$ promoter sequence [37], some SCN1A 5'-untranslated region, as well as Venus cDNA following the ATG start 


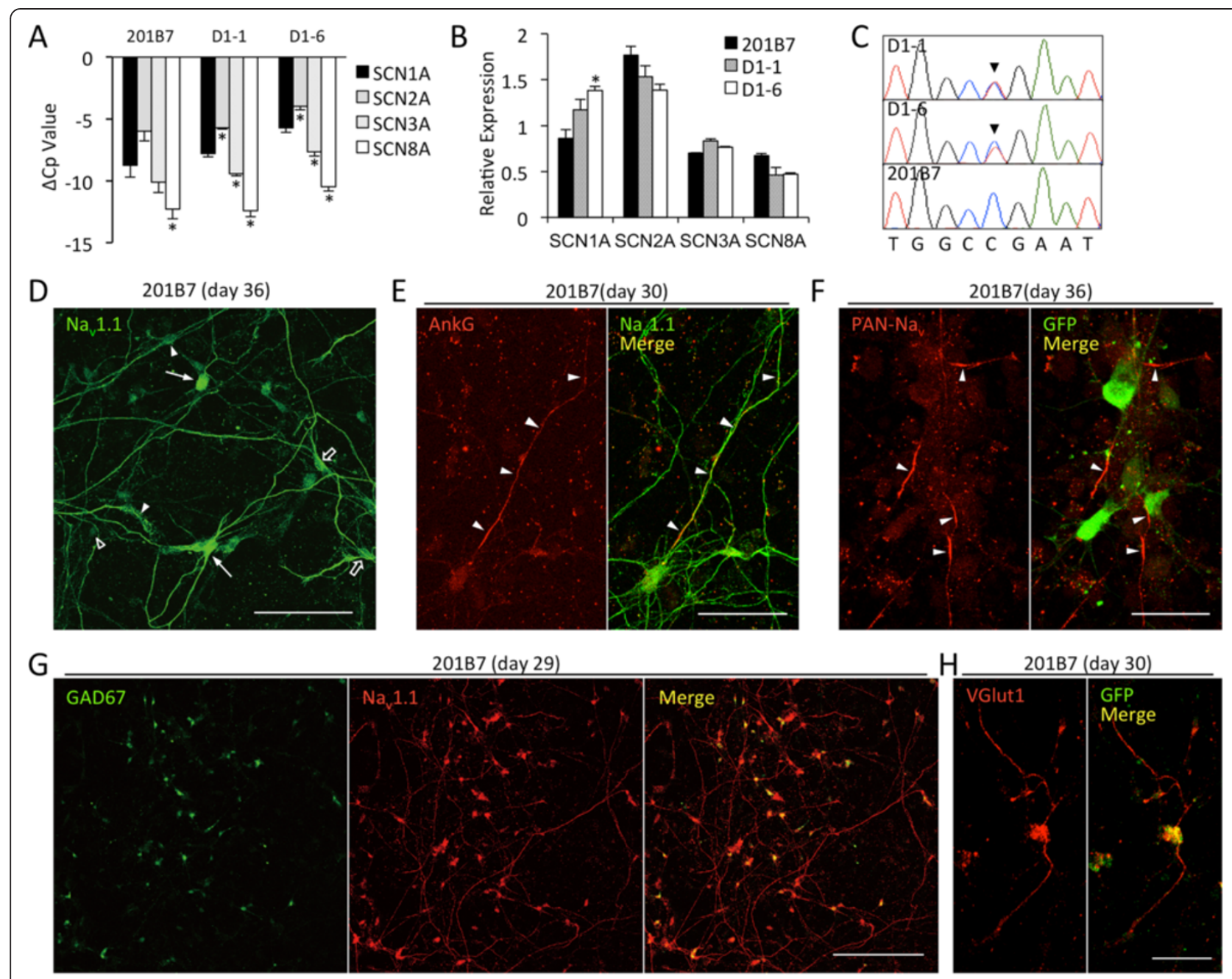

Figure $2 \mathrm{Na}_{\mathbf{v}}$ channel expression in iPSC-derived neurons. (A) Real-time PCR addressing neuronal $\mathrm{Na}_{\mathrm{v}}$ expression at 30 days of differentiation $\left(N=3\right.$ in each cell line) Crossing point differences to $\beta$-actin $\left(\triangle C p=C p^{\beta-a c t i n}-C p^{N a y}\right)$ closer to zero indicate higher expression. PCR efficiencies were nearly identical (Additional file 2). Asterisks indicate a significant difference to SCN1A $(P<0.5$, one-way ANOVA). Expression strength of the indicated $\mathrm{Na}_{\mathrm{v}}$ genes was constant across the cell lines $\left(P=0.92\right.$, two-way ANOVA) (B) Normalized expression levels for each $\mathrm{Na}_{v}$ gene (SCN1A + $S C N 2 A+S C N 3 A+S C N 8 A) / 4=1$. Compared to the control, SCN1A expression tended to be higher in D1-1 $(P=0.0929$, one-way ANOVA), and it was significantly higher in $\mathrm{D} 1-6\left({ }^{*} P=0.0078\right)$. The distribution of $\mathrm{Na}_{v}$ genes expression ratios in each cell line was significantly different between the control and the patient lines ( $P=0.0086$ and $<0.0001$ for D1-1 and D1-6, respectively, two-way ANOVA), but identical between D1-1 and D1-6 $(P=0.11)$. (C) Sequencing of SCN1A reverse transcribed mRNA isolated from iPSCs-derived neurons. Patient-neurons show a double peak at mutation site (solid arrowheads), confirming the heterozygous state of the cells (D) Immunocytochemical characterization of Nav 1.1 expression in control neurons: strong (solid arrows), moderate (open arrows), weak (solid arrowheads), and faint (open arrowhead). Despite weak staining in the cell body, neurite staining was often apparent (solid arrowheads). (E) Neurite co-localization of $\mathrm{Na}_{\mathrm{v}} 1.1$ and the AIS marker ankyrin $\mathrm{G}$ (AnkG, solid arrowheads). (F) PAN-Nav staining of SCN1A Venus-positive neurons (via anti-GFP, see Figure 3) in the AIS (arrowheads). (G) Co-localization of $\mathrm{Na}_{\mathrm{v}} 1.1$ and GAD67 staining. (H) VGlut1-positive neuron with SCN1A Venus expression. Scale bars: $100 \mu \mathrm{m}$ (D), $30 \mu \mathrm{m}(\mathbf{F}), 200 \mu \mathrm{m}(\mathbf{G})$ and $50 \mu \mathrm{m}$ (others).

codon (Figure 3A). This SCN1A-Venus construct was used to infect freshly plated cells from dissociated neurospheres. After several days of differentiation, SCN1A-Venus fluorescence developed in a few neurons, which further increased both, in the number of Venus-positive neurons and fluorescence intensity, as neuronal differentiation proceeded.

To confirm co-existence of $\mathrm{Na}_{\mathrm{v}} 1.1$ and Venus protein in the same cells, we employed immunostaining and found that most of the Venus-positive neurons also expressed $\mathrm{Na}_{\mathrm{v}} 1.1$ protein $(81 \%$ or $81 / 98$ in $201 \mathrm{~B} 7$ neurons, Figure 3B; $90.1 \%$ or $100 / 111$ in D1-1; and $78.8 \%$ or $93 / 118$ in D1-6, Additional file 8A). Furthermore, many SCN1A-Venuspositive neurons were also positive for GABA $(79.3 \%$ or $69 / 87$ in $201 B 7$ neurons, Figure $3 C$; $83.0 \%$ or $186 / 224$ in D1-1 neurons; and $70.3 \%$ or $152 / 216$ in D1-6, Additional file 8B), indicating GABAergic neurons. 


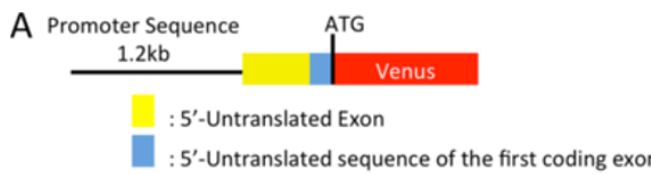

B

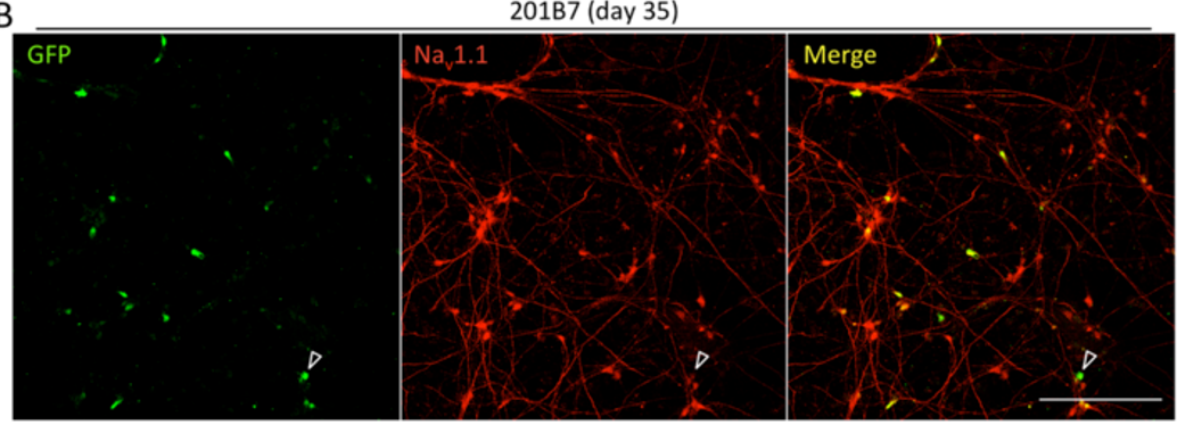

C

20187 (day 32)

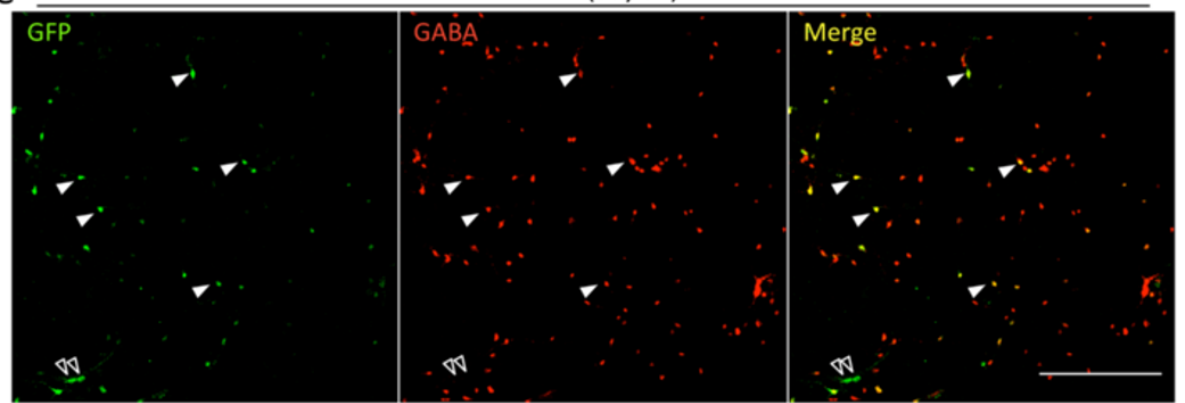

Figure 3 Structure and characterization of the lentiviral SCN1A-reporter used in the electrophysiological analyses. (A) The reporter comprised (5' to $\left.3^{\prime}\right)$ a 1.2-kb upstream sequence, a $5^{\prime}$-untranslated exon, the $5^{\prime}$-end of the first coding exon, and, following the ATG start codon, Venus CDNA. (B) \& (C) $201 B 7$ neurons labeled for Venus (using a GFP antibody) and Na 1.1 (B) or GABA (C). (B) Open arrowheads indicate GFP-pseudopositive neurons lacking Nav1.1 staining. (C) GFP-positive neurons with (arrowhead) and without GABA staining (open arrowhead). Scale bars: $200 \mu \mathrm{m}$.

\section{Neuron selection for electrophysiology}

To examine the electrophysiological behavior of control and patient-derived neurons, we conducted current-clamp experiments on cells $22-50$ days into neuronal differentiation; shorter differentiation times produced unreliable responses suggesting that the neurons had not fully matured. Hence, neuron selection for electrophysiological analysis was based on the following conditions: (1) clear SCN1A-Venus fluorescence; (2) mature neuronal morphology with a large and complex cell body and growth of $\geq 4$ neurites; (3) $\geq 30 \mathrm{pF}$ membrane capacitance; and (4) resting membrane potential at or more negative than $-30 \mathrm{mV}$.

Based on these criteria, a total of 48 and 27 neurons were recruited for patient-derived cell lines D1-1 and D1-6, respectively; 33 neurons were examined for the 201B7 control cell line. We first established cell capacitance and the resting membrane potential for all cells as indicators for neuron maturity in an effort to minimize inclusion of potentially inappropriate cell responses (Additional file 9A). We found that the resting membrane potential averagely fell between -40 and $-45 \mathrm{mV}$ without any statistically discernible difference between the cell lines. The neurons had membrane capacitance mostly up to $70 \mathrm{pF}$. Some outliers of $100+$ pF were also present, but they required excessive current injection to generate action potentials (Additional file 10), which prompted us to remove them from our analyses.

We next examined action potential generation in the current clamp configuration, using 10-ms depolarizing current injections from a holding potential of $-70-\mathrm{mV}$, and we found no statistical difference between patientderived and control neurons in terms of firing threshold and peak voltage (Additional file 9B).

We then determined the input-output relationship using sustained 500-ms injections of depolarizing current to trigger action potentials. In all cases, the number of action potentials per $500-\mathrm{ms}$ stimulation period increased with the intensity of the injected current. However, as current injection intensified, amplitude attenuation became apparent (Additional file 11A). This intensified up to a certain current injection level, where action potentials not only obviously declined in amplitude but also in number, to ultimately stop completely (depolarization block, 
Additional file 11B). Because depolarization block was common (Additional file 12), we suspected that electrically immature neurons were abundant among the cells we had selected for analysis. For further electrophysiological characterization, we therefore admitted neurons only, if they produced 10 or more action potentials.

\section{Action potential analysis}

The numbers of neurons for electrophysiological comparisons between cell lines were 12 in D1-1, 15 in D1-6, and 16 in 201B7. Capacitance, resting membrane potential, action potential threshold, and action potential peak voltage in control and patient-derived neurons were statistically indistinguishable (Figure 4A). However, most notably in the input-output relationship, both patientderived neuron cell lines frequently produced marked amplitude attenuation, which was not seen in control neurons (Figure 4B-C). Furthermore, both Dravet neuron cell lines showed a similar reduction in action potential firing at $>50 \mathrm{pA}$, which, too, was never observed in control cells (Figure 4D). Data of individual neurons (Additional file 13) show that a higher number of D1-1 (33.3\% or $4 / 12$ ) and D1-6 (46.7\% or $7 / 15)$ neurons reached their peak output prior to reaching a current of $100 \mathrm{pA}$ compared to $201 \mathrm{~B} 7$ (12.5\% or $2 / 16)$ neurons. These differences support functional impairment in the patient-derived neurons, especially in GABAergic neurons. The essence is a reduced output capacity during intense stimulation.

\section{Discussion}

In this study, we report on the generation of neurons from DS patient iPSCs. Gene expression and immunocytochemical analyses demonstrated that the control and the two patient cell lines contained neurons of identical character. Electrophysiological analysis of the patientderived cells revealed impairments in action potential generation in response to sustained current injection, especially with higher current intensities. Specifically, patient-derived iPSC neurons produced fewer action potentials with attenuated amplitudes and earlier depolarization
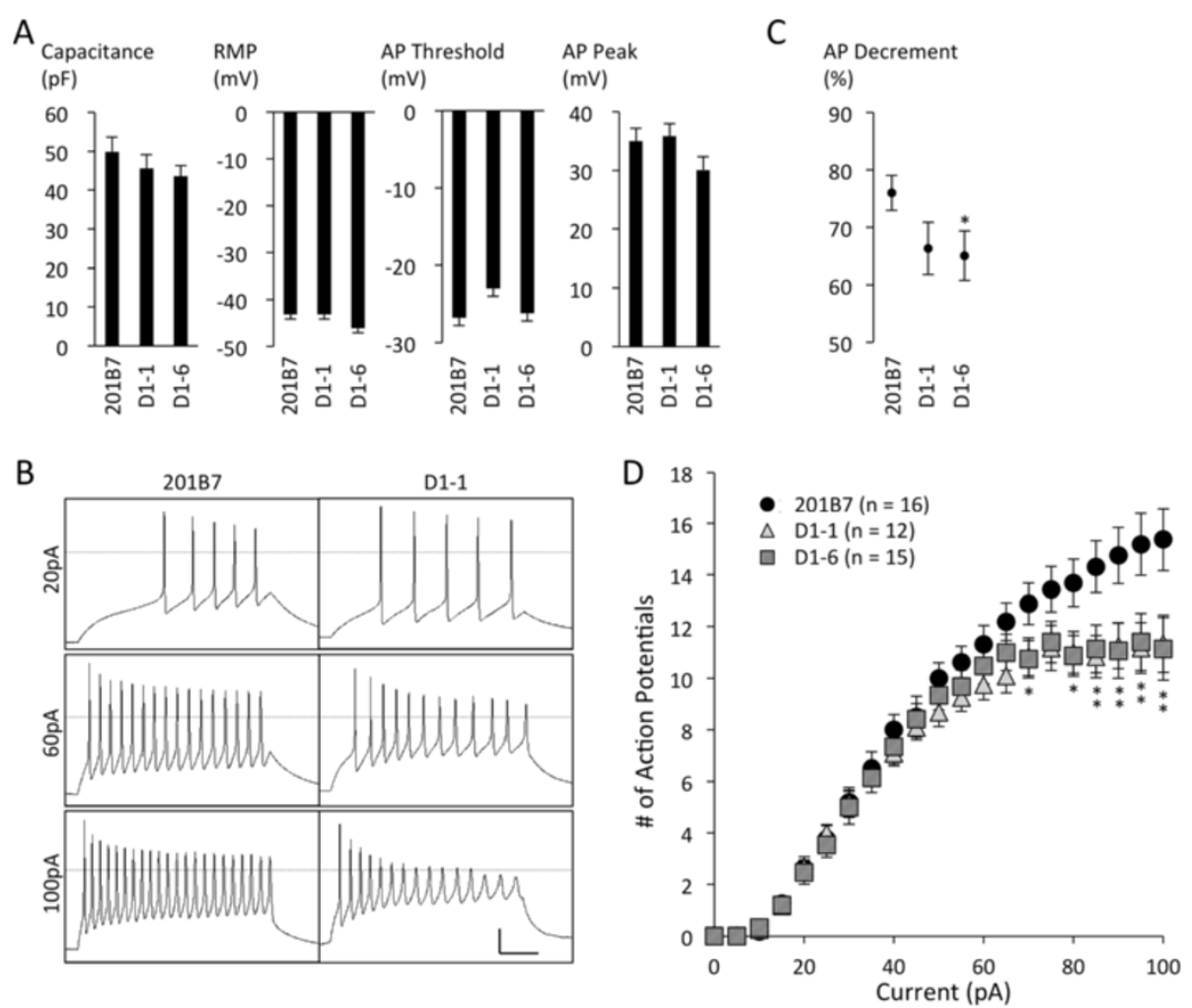

Figure 4 Electrophysiological characteristics of mature iPSC-derived neurons. (A) Capacitance, resting membrane potential (RMP), action potential (AP) firing threshold, and voltage peak were identical across all neurons analyzed ( $P>0.05$, Kruskal-Wallis test); error bars indicate S.E.M. (B) Representative traces of AP trains triggered by a 500-ms depolarizing current at the indicated intensities. Transverse dotted lines demark $0 \mathrm{mV}$ membrane potential. Scale bars: $20 \mathrm{mV}$ vs. $100 \mathrm{~ms}$. (C) Action potential (AP) decrement at current intensities triggering $>10$ APs calculated as a percentage: $10^{\text {th }} / 1^{\text {st }}$ AP amplitude. Control vs. D1-1 $(P=0.078)$ and D1-6 $\left({ }^{*} P=0.045\right.$, ANOVA); D1-1 vs. D1-6 $(P=0.839)(D)$ Total number of APs during the 500-ms stimulation period vs. current injection intensity. When exposed to strong current injections, both patient-derived cell lines produced significantly fewer APs compared to the control (the slope of AP numbers at $\geq 50$ pA, $P=0.0102$ and 0.0011 for D1-1 and D1-6, respectively, ANCOVA, ${ }^{*} P<0.05$ for D1-6 only, ${ }^{* *} P<0.05$ for both D1-1 and D1-6, Wilcoxon rank-sum test). 
block compared to control neurons. These results are reminiscent of the voltage responses seen in neurons isolated from rodent epilepsy models with SCN1A defects $[8,9,17,38]$ and they are consistent with DS pathophysiology that includes an inability of neurons to adequately respond to high-intensity stimulation. Although it was technically difficult to conclusively determine whether the $\mathrm{Na}_{\mathrm{v}} 1.1$-positive neurons were GABAergic or glutamatergic (likely due to cell population heterogeneity and low marker protein expression), data from immunocytochemical analyses suggest that the $\mathrm{Na}_{\mathrm{v}} 1.1$-positive neurons were mostly GABAergic. Furthermore, the majority of SCN1A Venus-positive neurons showed GABA immunostaining, which supports that the neurons undergoing electrophysiological analysis in this study were phenotypically homogeneous. We therefore interpreted our findings in the context of a functional decline in GABAergic neuron activity - defective inhibition. Of course, we cannot exclude involvement of other neuron types. In the context of the data presented here, however, it is possible that the pathophysiology of human and mouse Dravet syndrome employs similar mechanisms.

Several differences may exist between human and rodent brains with respect to $\mathrm{Na}_{\mathrm{v}} 1.1$ expression. In rodent cerebral cortex, $\mathrm{Na}_{\mathrm{v}} 1.1$ is predominantly expressed in the axon initial segment of GABAergic interneurons. Pyramidal neurons also express $\mathrm{Na}_{\mathrm{v}} 1.1[8,39,40]$, albeit at a minor level $[9,15]$. Furthermore, epilepsy models with $S C N 1 A$ defects have identified functional deficits in GABAergic interneurons, but not in pyramidal neurons $[8,9,41]$. In human brain, $\mathrm{Na}_{\mathrm{v}} 1.1$ expression differs from what is seen in rodents: $\mathrm{Na}_{\mathrm{v}} 1.1$ shows somatodendritic localization and expression in pyramidal neurons, specifically in cortical layer $\mathrm{V}$ and in the hippocampus [42-44]. This may be attributed to different experimental conditions and antibodies used, but, if rodent and human expression patterns indeed diverge, then it is conceivable that the associated pathophysiology differs as well. Pyramidal neurons use glutamate as their neurotransmitter, and our analyses showed that iPSCs-derived neurons expressing SCN1A-Venus were also positive for VGlut1. Unfortunately, the culture conditions in our study did not permit ready differentiation into glutamatergic neurons, which kept their number below what is usable for functional analyses. Functional characterization of nonGABAergic neurons must be addressed in the future to enhance our understanding of this DS model, and possibly unveil further pathogenic mechanisms.

With current methodology, establishing iPSC lines is labor- and time- consuming. Future research into human in vitro disease models may soon overcome these obstacles as other sources of pluripotent stem cells are considered, such as Nestin-expressing hair follicle stem cells $[45,46]$. They are easily accessible, they can be utilized without any genetic manipulation, and they have the potential to differentiate into neurons. If stable and efficient neural induction and maturation methods are established, for in vivo neuronal disease modeling will be possible.

\section{Conclusions}

With this study, we report the first successful generation of a human-based in vitro DS model. Our data are consistent with a functional decline in GABAergic neurons, which may contribute to DS epileptogenesis. The results are encouraging that patient-derived iPSC models can be utilized in human epilepsy research. They may, in fact, provide unparalleled insight into pathogenic mechanisms, and a uniquely suited research platform for drug development.

\section{Materials and methods}

\section{Isolation of human skin fibroblasts and generation of iPSCs}

Skin fibroblasts were isolated from a skin punch biopsy of the patient's upper arm with the approval by the Human Ethics Committee of Fukuoka University (Approval No. 361). The parents of the patient provided signed informed consent before the study. Fibroblasts were cultured in DMEM containing 10\% fetal bovine serum, $50 \mathrm{IU} / \mathrm{mL}$ penicillin, and $50 \mathrm{mg} / \mathrm{mL}$ streptomycin. The generation, maintenance, and characterization of iPSCs were performed as previously described $[26,47]$. Briefly, fibroblasts were lentivirus-trunsduced with Slc7a1 and plated at a density of $3.5 \times 10^{5}$ cells $/ 60-\mathrm{mm}$ dish. The next day, 4 reprogramming factors (Sox2, Klf4, Oct3/4, and $\mathrm{c}-\mathrm{Myc}$ ) were transduced using retroviruses. Seven days thereafter, the fibroblasts were re-plated at a density of $5 \times 10^{3}-5 \times 10^{5}$ cells/100-mm dish with a mitomycin C-treated SNL feeder layer. The SNL feeder cells were obtained from the Wellcome Trust Sanger Institute (Hinxton, England). The next day, the medium was replaced with human iPS medium, which was DMEM/F12 containing 20\% knockout serum replacement, $2 \mathrm{mM}$ L-glutamine, $0.1 \mathrm{mM}$ nonessential amino acids, $0.1 \mathrm{mM}$ 2-mercaptoethanol, $4 \mu \mathrm{g} / \mathrm{mL}$ basic FGF (R\&D Systems, Minneapolis, MN), $50 \mathrm{IU} / \mathrm{mL}$ penicillin, and $50 \mathrm{mg} / \mathrm{mL}$ streptomycin. The medium was changed either daily or every other day until iPSC colonies were isolated, 24-28 days from the transduction of the reprogramming factors. iPSC clones were selected based on reprogramming transgene silencing (real-time PCR), colony morphology, expression of markers for undifferentiated cells (immunocytochemistry), pluripotency (teratoma formation), and neural induction efficiency. For iPSC maintenance, the medium was changed daily, and the cells passaged every 4-7 days depending on colony size. iPSCs passaged $<32$ times were used for neural induction. 
Details on the PCR conditions for SCN1A, SCN2A, $S C N 1 B$, and $S C N 2 B$ sequencing are available on request. The control iPSCs, 201B7, were provided by the RIKEN BioResource Center through the Project for Realization of Regenerative Medicine and the National Bio-Resource Project of the Ministry of Education, Culture, Sports, Science \& Technology (MEXT) in Japan. iPSC production was approved by the Keio University School of Medicine Ethics Committee (Approval No. 20-16-18) and the Human Ethics Committee of Fukuoka University (Approval No. 361).

\section{Neuronal differentiation of human iPSCs}

Neuronal differentiation of human iPSCs was performed as previously described [48] with minor modifications $[19,22,49]$. Briefly, iPSC colonies were detached from feeder layers, and were cultured in suspension as embryoid bodies (EBs) for about 30 days in bacteriologic dishes (Kord-Valmark/Myers, Akron, OH). For neurosphere formation, EBs were enzymatically dissociated and the single cells were cultured in suspension in the serumfree neurosphere medium (media-hormone-mix) for 10 to 14 days. The resulting neurospheres could be repeatedly passaged using the dissociation procedures described above. Neurospheres passaged 1-3 times were used for analysis. For ventralization of neuronal properties in some preliminary assays, 5 or $30 \mathrm{nM}$ of sonic hedgehog (R\&D Systems, Minneapolis, MN) or $1 \mu \mathrm{M}$ of purmorphamine (EMD Millipore, Billerica, MA) were added to the medium during the later phase of embryoid body and/or neurosphere formation. For terminal differentiation, neurospheres were plated onto poly-L-ornithine/ fibronectin-coated coverslips in a media-hormone-mix supplemented with B27 supplement. Dissociated cells were plated at an approximate density of $1 \times 10^{5} \mathrm{cells} / \mathrm{cm}^{2}$. Both dissociated and undissociated cells were cultured for varying periods depending on the assay. To enhance cell viability and to promote neuronal maturation, the differentiation medium was supplemented as follows: $10 \mathrm{ng} / \mathrm{mL}$ rhBDNF and rhGDNF (R\&D Systems), and $200 \mu \mathrm{g} / \mathrm{mL}$ L-ascorbic acid (Sigma-Aldrich, St. Louis, MO). Attempts to induce parvalbumin-positive neurons were made with $100 \mathrm{ng} / \mathrm{mL}$ of BMP4 (R\&D Systems) on day 10 of neuronal differentiation and continued until the assay was conducted.

\section{RNA isolation, reverse transcription, and real-time PCR analysis}

Total cellular RNA was extracted using TRIZOL Reagent (Life Technologies, Carlsbad, CA), RNase-Free DNase Set (Qiagen, Venlo, Netherlands), and RNeasy Mini or Micro Kits (Qiagen). Complimentary DNA synthesis was performed using the SuperScript III First-Strand Synthesis System for RT-PCR (Life Technologies) with oligo-dT primers from $0.2-1.0 \mu \mathrm{g}$ of total RNA, according to the manufacturer's guidelines. To analyze the relative expression of different mRNAs, the amount of cDNA was normalized to $\beta$-actin mRNA expression. The mRNA expression levels in iPSC-derived neurons were determined from at least three separately cultivated samples. Real-time PCR was performed using the LightCycler 480 System II (Roche Diagnostics, Basel, Switzerland) with the SYBR Premix Ex Taq (Takara Bio, Shiga, Japan). Primer sequences for real-time PCR are listed in Table 1.

\section{Immunocytochemistry}

Cells on coverslips were fixed with $4 \%$ paraformaldehyde for 10-30 $\mathrm{min}$ at room temperature, followed by washing 3 times with PBS. After incubating with blocking buffer (PBS containing 5\% normal goat or fetal calf serum and $0.1-0.3 \%$ triton $\mathrm{X}-100$ ) for $1 \mathrm{~h}$ at room temperature, the cells were incubated overnight at $4^{\circ} \mathrm{C}$ with primary antibodies diluted with the blocking buffer. Details of primary antibodies and the dilution conditions are presented below. The cells were then washed 3 times with PBS and incubated with secondary antibodies conjugated with Alexa Fluor 488 or Alexa Fluor 555 (1:500, Life Technologies) and Hoechst33342 $(2 \mu \mathrm{g} / \mathrm{mL}$, Dojindo Laboratories, Kumamoto, Japan) for $1 \mathrm{~h}$ at room temperature. After washing 3 times with PBS and a single wash with distilled water, the coverslips were mounted on slides with FluorSave Reagent (EMD Millipore/Merck Group). Images were acquired using a confocal laser-scanning microscope, FV1000-D (Olympus, Tokyo, Japan). Observation through $20 \times$ objective was used to determine whether $\mathrm{Na}_{\mathrm{v}} 1.1$-positive neurons were also positive for GAD67, calretinin, or GFP (for detection of Venus).

\section{Primary antibodies used in immunocytochemistry}

Anti- $\mathrm{Na}_{\mathrm{v}} 1.1$ (rabbit IgG, 1:500, Cat No. ASC-001 Alomone Labs, Israel). This antibody targets the peptide TASEHSREPSAAGRLSD, which corresponds to amino acids 465-481 in the internal D1-D2 linker human fulllength $\mathrm{Na}_{\mathrm{v}} 1.1$ (Reference sequence: NP_001159435.1). Anti-Sodium Channel 'PAN' (mouse IgG $_{1}$, 1:100, Cat No. S8809 - Sigma-Aldrich, St. Louis, MO) targets the peptide TEEQKKYYNAMKKLGSKK in the intracellular D3-D4 linker of $\mathrm{Na}_{\mathrm{v}}$ channels which is identical in all known vertebrate $\mathrm{Na}_{\mathrm{v}}$ channel isoforms. Anti-SSEA1 (mouse IgM, 1:500, Cat No. ab16285 - Abcam, Cambridge, MA), anti-SSEA4 (mouse IgG3, 1:500, ab16287 - Abcam), anti-TRA-1-60 (mouse IgM, 1:1000, Cat No. MAB4369 EMD Millipore, Billerica, MA USA), anti-TRA-1-81 (mouse IgM, 1:1000, MAB4381 - EMD Millipore), antiOct3/4 (Rb IgG, 1:500, Cat No. sc-9081 - Santa Cruz Biotechnology, Santa Cruz, CA), anti-Nanog (rabbit IgG, 1:100, Cat No.RCAB0001P - Cosmo Bio, Carlsbad, CA), anti- $\beta$ III-tubulin (mouse $\operatorname{IgG}_{2 \mathrm{~b}}, 1: 1000$, Cat No. 
Table 1 Primer details for real-time PCR

\begin{tabular}{lll}
\hline Target & Forward & Reverse \\
\hline$\beta$-actin & GATCAAGATCATTGCTCCTCCT & GGGTGTAACGCAACTAAGTCA \\
Sox2 $\left(\mathrm{tg}^{*}\right)$ & ACGGCCATTAACGGCACACTG & CCCTTITTCTGGAGACTAAATAAA \\
KIf4 $(\mathrm{tg})$ & CACCTCGCCTTACACATGAAGAG & \\
Oct3/4 $(\mathrm{tg})$ & TCTGGGCTCTCCCATGCATTCAAAC & \\
c-Myc $(\mathrm{tg})$ & CTTGAACAGCTACGGAACTCTTG & \\
SCN1A & AACAGAATCAGGCCACCTTG & CACTGGGCTCTCTGGAATG \\
SCN2A & GCTACACGAGCTTGACACC & CCCAAGAAAATGACCAGCAC \\
SCN3A & ATGGTGGGTTCCTTGGTG & TGACTTCCGTTCTGTGGTG \\
SCN8A & GGACCCATGGAACTGGTTAG & ACCCTGAAAGTGCGTAGAGC \\
Nkx2.1 & AGCACACGACTCCGTTCTCA & CCCTCCATGCCCACTTTCTT \\
Parvalbumin & CTGGACAAGGACAAAAGTGG & ACAGGTCTCTGGCATCTGG \\
\hline
\end{tabular}

All sequences are displayed in 5'-to-3' direction. ${ }^{*} \operatorname{tg}$, transgene.

T8660 - Sigma-Aldrich, St. Louis, MO), anti-GFAP (rabbit IgG, 1:4000, Cat No. Z0334 - Dako, Denmark), anti-GFP (mouse $\operatorname{IgG}_{2 \mathrm{a}}, 1: 100$, A11120 - Life Technologies, Carlsbad, CA, or rabbit IgG, 1:500, gift from Dr. Y. Misumi, Fukuoka University), anti-Ankyrin G (mouse $\operatorname{IgG}_{1}, 1: 100,33-8800$ - Life Technologies), antiGAD67 (mouse IgG Ia $_{1}$ 1:2000, MAB5406 - EMD Millipore), anti-Parvalbumin (mouse $\operatorname{IgG}_{1}, 1: 1000$, MAB1572 - EMD Millipore), anti-Somatostatin (Rat $\operatorname{IgG}_{2 \mathrm{~b}}, 1: 100$, ab30788 Abcam), anti-Calretinin (mouse, 1:1000, Cat No. 6B3 Swant, Switzerland), anti-VGlut1 (rabbit IgG, 1:1000, Cat No. 135303 - Synaptic Systems, Germany), and antiGABA (rabbit IgG, 1:2000, A2052- Sigma-Aldrich).

\section{Generation of SCN1A reporter lentivirus}

The upstream genomic sequence of an SCN1A $5^{\prime}$-untranslated exon (previously referred to as "h1b" by Martin, et al.[50], or "hB" by Nakayama, et al.[37]) was used as SCN1A promoter sequence. The 1,200-bp sequence stretch showed strong promoter activity and was obtained from the patient's genomic DNA. Aforementioned untranslated exon connected with the $5^{\prime}$-end of the first coding exon, which was obtained from D1-1 iPSC-derived neuronal cDNA. These fragments were connected via PCR and transferred into the pSIN-Venus vector, which has a cloning site connected to Venus cDNA (constructed by Y. Okada, Keio University). For lentivirus production, the pSIN construct, pLP1, pLP2, and pLP/VSVG plasmids (Life Technologies) were mixed and transfected into 293FT cells using CalPhos Mammalian Transfection Kit (Clontech/Takara Bio) or Lipofectamine 2000 Reagent (Life Technologies). The medium was changed the following day. Two days thereafter, the virus-containing medium was collected, filtered, and ultracentrifuged at 25,000 rpm with an SW 28 Rotor (Beckman Coulter, Brea, CA USA), at $4^{\circ} \mathrm{C}$ for $90 \mathrm{~min}$. The viral pellet was resuspended in $1 / 200$ of the original medium volume with media-hormone-mix, aliquoted, and stored at $-80^{\circ} \mathrm{C}$ until use.

\section{Electrophysiological analysis}

Electrophysiological analysis employed room temperature current-clamping of iPSC-derived neurons in the whole-cell configuration. Cell micrographs were produced with an upright microscope (BX51WI - Olympus, Melville, $\mathrm{NY}$ ) equipped with a CMOS image sensor camera, OR CA-Flash2.8 (Hamamatsu Photonics, Japan). Reporter fluorescence Venus was detected through a 40x waterimmersion objective (LUMPlanFI/IR2 - Olympus) with a U-MGFPHQ cube (excitation: 460-480 nm, dichroic mirror: $485 \mathrm{~nm}$, emission: 495-540 nm - Olympus) and processed with Aquacosmos software (Hamamatsu, Japan). The extracellular solution contained $150 \mathrm{mM} \mathrm{NaCl}, 4 \mathrm{mM}$ $\mathrm{KCl}, 2 \mathrm{mM} \mathrm{CaCl} 2,2 \mathrm{mM} \mathrm{MgCl} \cdot 6 \mathrm{H}_{2} \mathrm{O}, 10 \mathrm{mM}$ HEPES, and $10 \mathrm{mM}$ glucose adjusted to $\mathrm{pH} 7.4$ with $\mathrm{NaOH}$. Patch pipettes were made from borosilicate glass with filament (Cat No. FB150-86-0 - Sutter Instruments, Novato, CA) and pulled to resistances of 2-4 M $\Omega$ (P-97, Sutter Instruments) when filled with $0.22-\mu \mathrm{m}$ filtered intracellular solution of the following composition: $117 \mathrm{mM} \mathrm{K}$ methanesulfonate, $9 \mathrm{mM}$ EGTA, $9 \mathrm{mM}$ HEPES, $1.8 \mathrm{mM}$ $\mathrm{MgCl}_{2} \cdot 6 \mathrm{H}_{2} \mathrm{O}, 29 \mathrm{mM}$ sucrose, $4 \mathrm{mM} \mathrm{Mg-ATP,} 0.3 \mathrm{mM}$ Tris-GTP, and $5 \mathrm{mM} \mathrm{KCl}$ adjusted to $\mathrm{pH} 7.3$ with $\mathrm{KOH}$. Whole-cell patch-clamp recordings were carried out using an Axopatch 700B amplifier (Axon Instruments, Sunnyville, CA) and pCLAMP 10 software (Axon Instruments). Signals were low-pass Bessel filtered at $10 \mathrm{kHz}$ and sampled at a $50 \mathrm{kHz}$ with an Axon Digidata 1440A digitizer (Axon Instruments). Cell capacitance was calculated by integrating the capacitive current evoked by a $10-\mathrm{mV}$ depolarizing pulse from a holding potential of $-65 \mathrm{mV}$. The resting membrane potential was determined from the mean potential during a 10-s continuous recording in zero-current clamp mode. During current- 
clamp experiments, cells were held at $-70 \mathrm{mV}$ by constant current injection, as needed. Single action potentials, operationally defined to minimally reach $0 \mathrm{mV}$, were evoked by current injection $(10 \mathrm{~ms})$ to determine their firing thresholds and peak voltages. The injection current amplitude was increased in 10-pA increments from sub- to suprathreshold. To investigate the input-output relationship, sustained depolarizing currents $(500 \mathrm{~ms})$ were injected and the current amplitude was increased from 5 to $100 \mathrm{pA}$ in 5 -pA increments. Final data was taken from neurons on at least 8 coverslips of at least 4 separately cultivated samples in each clone. Electrophysiological data were analyzed using pCLAMP 10 software (Axon Instruments, Sunnyvale, CA).

\section{Statistical analysis}

All of the data analyses were performed using SAS (Statistical Analysis System) Software Package (Ver. 9.2, SAS Institute Inc., Cary, NC) at Fukuoka University (Fukuoka Japan). $\mathrm{Na}_{\mathrm{v}}$ gene expression was compared with oneway ANOVA (between $\mathrm{Na}_{\mathrm{v}}$ channel genes) and two-way ANOVA (between iPSC clones). Cell capacitance, resting membrane potential, action potential firing threshold, peak voltage, action potential decrement, and area under the input-output relationship curve were compared among the clones using one-way ANOVA (with Scheffe's post hoc test) and/or the Kruskal-Wallis test. The action potential number for each injection level in the input-output relationship was compared between the clones using the Wilcoxon rank-sum test. The slope of the number of action potentials $v s$. injected current in Figure 4C was compared using ANCOVA. Data are presented as mean \pm standard error of the mean (S.E.M.), and P-values $<0.05$ were deemed significant.

\section{Additional files}

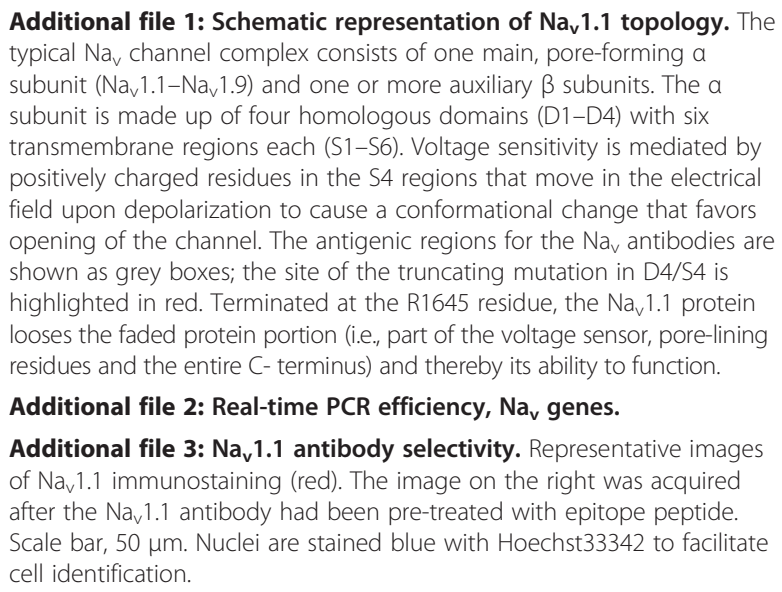

Additional file 4: Characterization of patient-derived neurons. (A) Intense expressions of PAN-Na in the axon initial segment (solid arrowheads) of SCN1A Venus-positive neurons. (B) Co-localization of $\mathrm{Na}_{\mathrm{v}} 1.1$ and GAD67 staining. (C) VGlut1-positive neuron co-localized with SCN1A Venus (solid arrowheads). Scale bars: $30 \mu \mathrm{m}$ (A), $200 \mu \mathrm{m}$ (B), and $50 \mu \mathrm{m}(\mathrm{C})$.

Additional file 5: Characterization of $\mathrm{Na}_{\mathrm{v}}$ 1.1-positive neurons. (a) Calretinin-positive neurons with (arrowhead) and without $\mathrm{Na}_{v} 1.1$ staining (open arrowhead). Scale bar, $50 \mu \mathrm{m}$. (b) Somatostatin-positive neurons are negative for $\mathrm{Na}_{v} 1.1$. Scale bar, $100 \mu \mathrm{m}$.

Additional file 6: RT-PCR of parvalbumin mRNA from iPSCs-derived neurons. 180-bp bands are indicated beta-actin mRNA expression. 85-bp bands demark parvalbumin (PV). When total RNA was used as template (RT-), no product was generated.

Additional file 7: Increase in Nkx2.1 mRNA expression following treatment with sonic hedgehog $(\mathrm{SHH})$ or purmorphamine. (a) During embryoid body formation (approx. 20-30 days) of cell line D1-1, the growth medium was supplemented with $\mathrm{SHH}$ to the indicated concentrations. This resulted in a dose-related increase in Nkx2.1 mRNA expression. Data from two different setups were averaged and normalized to the control (0 nM SHH); error bars are S.E.M. (b) Similar setup as in Panel (a), but SHH was added during neurosphere (NS) formation; cell line D1-6. This produced an increase in Nkx2.1 mRNA expression, although apparently not in dose-dependent fashion, which may relate to $\mathrm{SHH}$ only maintaining $\mathrm{Nkx} 2.1$ expression rather than inducing new ventral neuronal precursors. (c) Setup similar to Panel (a), albeit with purmorphamine treatment.

Additional file 8: $\mathrm{Na}_{\mathrm{v}} 1.1$ and GABA expression in SCN1A Venuspositive patient neurons. Venus was detected using a GFP antibody. (A) Venus-positive neurons lacking $\mathrm{Na}_{v} 1.1$ staining, open arrowheads. (B) Venus-positive neurons with (solid arrowheads) and without GABA staining (open arrowhead). Scale bars: $200 \mu \mathrm{m}$.

Additional file 9: Electrophysiological characteristics of all recruited iPSC-derived neurons. (A) Capacitance \& resting membrane potential (RMP) and (B) action potential (AP) firing threshold \& voltage peak. No statistical differences were found in all items $(P>0.05$, Kruskal-Wallis test). Error bars indicate S.E.M.

Additional file 10: Input-output relationship of large ( $\geq 100 \mathrm{pF})$ control neurons. Current clamping as in Figure 4. This produced a set number of action potentials per 500-ms stimulation period, which was plotted against the injected current amplitude. Note the size-dependent increase in the current required to trigger the same number of action potentials compared to smaller neurons (average for Figure 4C depicted in bold).

Additional file 11: Illustration of "action potential attenuation" and "depolarization block" in current-clamped neurons. (A) The number of action potentials increased with stronger current injections but a simultaneous tapering of action potential amplitude was apparent. (B) Action potential tapering reached a state where further firing was prevented despite continued stimulation. Rectangular pulses represent current injection periods (500 ms) at the indicated intensities.

Additional file 12: Example current-clamp traces of $201 \mathrm{~B} 7$ control neurons with immature voltage responses. 500-ms depolarizing currents were injected at the indicated intensities. Transverse dotted lines demark $0 \mathrm{mV}$ membrane potential. Scale bars, $20 \mathrm{mV}$ vs. $100 \mathrm{~ms}$.

Additional file 13: Individual input-output relationship plots for control and Dravet-derived neurons. Experimental setup and plotting as in Additional file 6. Each line plot represents one cell. Current injections of $<100 \mathrm{pA}$ frequently maxed out the number of action potentials triggered in patient neurons (D1-1 and D1-6), but only rarely in the control neurons (201B7).

\section{Competing interests}

The authors declare that they have no competing interests.

\section{Authors' contributions}

$\mathrm{NH}$ designed, executed, and directed the study, and wrote the paper. TU performed all electrophysiological assays. $\mathrm{CL}$ designed the electrophysiological analyses and contributed to the writing of the 
manuscript. MM and SK assisted with the electrophysiological assay methods and helped with data interpretation. YM contributed to the immunocytochemical analysis. $\mathrm{YO}, \mathrm{Yl}$ and WA contributed to all cell culture and biologic assay procedures. KN performed the pathologic analysis of the iPSC-derived teratomas. BZ performed statistical analysis. YS contributed to clinical and genetic analysis of the patient. $\mathrm{HO}$ and $\mathrm{SH}$ coordinated the study. All authors read and approved the final manuscript.

\section{Acknowledgements}

The authors thank the patient and parents for their cooperation in this study. We are indebted to Ms. Akiyo Hamachi and Ms. Minako Yonetani for excellent technical assistance. This work was supported in part by a Grants-in -Aid for Scientific Research (A) (21249062), for Challenging Exploratory Research (23659529 and 2570481), for Scientific Research on Innovative Areas, and for Bilateral Joint Research Projects from Japan Society for the Promotion of Science (JSPS) to S.H.; a Grant-in-Aid for Scientific Research on Innovative Areas "Genome Science" to S.H.; a Grant-in-Aid for Young Scientists (B) (24791095) from JSPS to N.H.; a Grant-in-Aid for the Adaptable and Seamless Technology Transfer Program through Target-driven R\&D (A-STEP) Exploratory Research from Japan Science and Technology Agency (JST) to S.H.; Research Grants for Nervous and Mental Disorder (21B-5), Health and Labor Science Research Grant (21210301 and KB220001), and a Grantin-aid for the Research on Measures for Intractable Diseases (No. H22Nanji-Ippan-49) from the Ministry of Health, Labor and Welfare (MHLW) to S. H.; the Project for the Realization of Regenerative Medicine from the Japanese Ministry of Education, Culture, Sports, Science and Technology (MEXT) to H.O.; The Program for Intractable Disease Research utilizing Disease-specific iPS Cells from JST to H.O. Research grants from The Japan Foundation for Pediatric Research (10-003), The Clinical Research Promotion Foundation, and Kaibara Morikazu Medical Science Promotion Foundation to N.H.; Research grants from The Japan Epilepsy Research Foundation to N.H. and T.U.; and Research grants from the 2013-2017 "Central Research Institute for the Molecular Pathomechanisms of Epilepsy of Fukuoka University" and Recommended Projects of Fukuoka University (117016) to S.H.

\section{Author details}

'Department of Pediatrics, School of Medicine, Fukuoka University, 45-1, 7-chome, Nanakuma, Jonan-ku, Fukuoka 814-0180, Japan. ${ }^{2}$ Central Research Institute for the Pathomechanisms of Epilepsy, Fukuoka University, Fukuoka, Japan. ${ }^{3}$ Department of Pediatrics, Jikei University Scool of Medicine, Tokyo, Japan. ${ }^{4}$ Department of Neurology, University of California, Sacramento, CA, USA. ${ }^{5}$ Department of Cell Biology, Fukuoka University School of Medicine, Fukuoka, Japan. ${ }^{6}$ Department of Physiology, Keio University School of Medicine, 35 Shinanomachi, Shinjuku-ku, Tokyo 160-8582, Japan. ${ }^{7}$ Kanrinmaru-Project, Keio University School of Medicine, 35 Shinanomachi, Shinjuku-ku, Tokyo 160-8582, Japan. ${ }^{8}$ Department of Biochemistry, Fukuoka University School of Medicine, Fukuoka, Japan. ${ }^{9}$ Department of Pathology, Fukuoka University School of Medicine, Fukuoka, Japan. ${ }^{10}$ Department of Physiology, Fukuoka University School of Medicine, Fukuoka, Japan. ${ }^{11}$ Department of Neuropharmacology, Faculty of Pharmaceutical Sciences, Fukuoka University, Fukuoka, Japan. ${ }^{12}$ Shirasaka Clinic, Kobe, Japan.

\section{Received: 8 February 2013 Accepted: 3 April 2013}

Published: 2 May 2013

\section{References}

1. Dravet C, Bureau M, Oguni H, Fukuyama Y, Cokar O: Severe myoclonic epilepsy in infancy (Dravet syndrome). In Epileptic syndromes in infancy, childhood and adolescence. 4th edition. Edited by Roger J, Bureau M, Dravet C, Genton P, Tassinari CA, Wolf P. Montrouge: John Libbey Eurotext; 2005:89-113.

2. Genton $P$, Velizarova $R$, Dravet $C$ : Dravet syndrome: the long-term outcome. Epilepsia 2011, 52(Suppl 2):44-49.

3. Sakauchi M, Oguni H, Kato I, Osawa M, Hirose S, Kaneko S, Takahashi Y, Takayama R, Fujiwara T: Retrospective multiinstitutional study of the prevalence of early death in Dravet syndrome. Epilepsia 2011, 52:1144-1149.

4. Depienne C, Trouillard O, Saint-Martin C, Gourfinkel-An I, Bouteiller D, Carpentier W, Keren B, Abert B, Gautier A, Baulac S, et al: Spectrum of SCN1A gene mutations associated with Dravet syndrome: analysis of 333 patients. J Med Genet 2009, 46:183-274.
5. Marini C, Scheffer I, Nabbout R, Suls A, De Jonghe P, Zara F, Guerrini R: The genetics of Dravet syndrome. Epilepsia 2011, 52(Suppl 2):24-33.

6. Spampanato J, Escayg A, Meisler M, Goldin A: Functional effects of two voltage-gated sodium channel mutations that cause generalized epilepsy with febrile seizures plus type 2. J Neurosci 2001, 21:7481-7571.

7. Lossin C, Rhodes T, Desai R, Vanoye C, Wang D, Carniciu S, Devinsky O, George A: Epilepsy-associated dysfunction in the voltage-gated neuronal sodium channel SCN1A. J Neurosci 2003, 23:11289-11384.

8. Yu F, Mantegazza M, Westenbroek R, Robbins C, Kalume F, Burton K, Spain W, McKnight G, Scheuer T, Catterall W: Reduced sodium current in GABAergic interneurons in a mouse model of severe myoclonic epilepsy in infancy. Nat Neurosci 2006, 9:1142-1151.

9. Ogiwara I, Miyamoto H, Morita N, Atapour N, Mazaki E, Inoue I, Takeuchi T, Itohara S, Yanagawa Y, Obata K, et al: $\mathrm{Na}_{\mathrm{v}} \mathrm{1} .1$ localizes to axons of parvalbumin-positive inhibitory interneurons: a circuit basis for epileptic seizures in mice carrying an Scn 1a gene mutation. J Neurosci 2007, 27:5903-5917.

10. Cheah CS, Yu FH, Westenbroek RE, Kalume FK, Oakley JC, Potter GB, Rubenstein JL, Catterall WA: Specific deletion of $\mathrm{Na}_{\mathrm{v}} 1.1$ sodium channels in inhibitory interneurons causes seizures and premature death in a mouse model of Dravet syndrome. Proc Natl Acad Sci USA 2012, 109:14646-14651.

11. Han S, Tai C, Westenbroek RE, Yu FH, Cheah CS, Potter GB, Rubenstein JL, Scheuer T, de la Iglesia HO, Catterall WA: Autistic-like behaviour in Scn1a+/mice and rescue by enhanced GABA-mediated neurotransmission. Nature 2012, 489:385-390

12. Meisler M, Kearney J: Sodium channel mutations in epilepsy and other neurological disorders. J Clin Invest 2005, 115:2010-2017.

13. Suls A, Claeys K, Goossens D, Harding B, Van Luijk R, Scheers S, Deprez L, Audenaert D, Van Dyck T, Beeckmans $S$, et al: Microdeletions involving the SCN1A gene may be common in SCN1A-mutation-negative SMEI patients. Hum Mutat 2006, 27:914-934.

14. Bechi G, Scalmani P, Schiavon E, Rusconi R, Franceschetti S, Mantegazza M: Pure haploinsufficiency for Dravet syndrome $\mathrm{Na}(\mathrm{V}) 1.1$ (SCN1A) sodium channel truncating mutations. Epilepsia 2012, 53:87-187.

15. Lorincz A, Nusser Z: Molecular identity of dendritic voltage-gated sodium channels. Sci (New York, NY) 2010, 328:906-915.

16. Lewis DA, Hashimoto T, Volk DW: Cortical inhibitory neurons and schizophrenia. Nat Rev Neurosci 2005, 6:312-324.

17. Martin M, Dutt K, Papale L, Dubé C, Dutton S, de Haan G, Shankar A, Tufik S, Meisler M, Baram T, et al: Altered function of the SCN1A voltage-gated sodium channel leads to gamma-aminobutyric acid-ergic (GABAergic) interneuron abnormalities. J Biol Chem 2010, 285:9823-9857.

18. Soldner F, Hockemeyer D, Beard C, Gao Q, Bell G, Cook E, Hargus G, Blak A, Cooper O, Mitalipova M, et al: Parkinson's disease patient-derived induced pluripotent stem cells free of viral reprogramming factors. Cell 2009, 136:964-1041.

19. Yagi T, Ito D, Okada Y, Akamatsu W, Nihei Y, Yoshizaki T, Yamanaka S, Okano H, Suzuki N: Modeling familial Alzheimer's disease with induced pluripotent stem cells. Hum Mol Genet 2011, 20:4530-4539.

20. Marchetto M, Carromeu C, Acab A, Yu D, Yeo G, Mu Y, Chen G, Gage F, Muotri A: A model for neural development and treatment of Rett syndrome using human induced pluripotent stem cells. Cell 2010, 143:527-566.

21. Brennand K, Simone A, Jou J, Gelboin-Burkhart C, Tran N, Sangar S, Li Y, Mu Y, Chen G, Yu D, et al: Modelling schizophrenia using human induced pluripotent stem cells. Nature 2011, 473:221-226.

22. Imaizumi Y, Okada Y, Akamatsu W, Koike M, Kuzumaki N, Hayakawa H, Nihira T, Kobayashi T, Ohyama M, Sato S, et al: Mitochondrial dysfunction associated with increased oxidative stress and alpha-synuclein accumulation in PARK2 iPSC-derived neurons and postmortem brain tissue. Mol Brain 2012, 5:35.

23. Nihei Y, Ito D, Okada Y, Akamatsu W, Yagi T, Yoshizaki T, Okano H, Suzuki N: Enhanced aggregation of androgen receptor in induced pluripotent stem cell-derived neurons from spinal and bulbar muscular atrophy. J Biol Chem 2013, 288:8043-8052.

24. Wakai S, Ikehata M, Nihira H, Ito N, Sueoka H, Kawamoto Y, Hayasaka H, Chiba S: "Obtundation status (Dravet)" caused by complex partial status epilepticus in a patient with severe myoclonic epilepsy in infancy. Epilepsia 1996, 37:1020-1022.

25. Fukuma G, Oguni H, Shirasaka Y, Watanabe K, Miyajima T, Yasumoto S, Ohfu M, Inoue T, Watanachai A, Kira R, et al: Mutations of neuronal voltage-gated $\mathrm{Na}^{+}$ 
channel alpha 1 subunit gene SCN1A in core severe myoclonic epilepsy in infancy (SMEI) and in borderline SMEI (SMEB). Epilepsia 2004, 45:140-148.

26. Takahashi K, Tanabe K, Ohnuki M, Narita M, Ichisaka T, Tomoda K, Yamanaka S: Induction of pluripotent stem cells from adult human fibroblasts by defined factors. Cell 2007, 131:861-872.

27. Maquat LE: Nonsense-mediated mRNA decay in mammals. J Cell Sci 2005, 118:1773-1776.

28. Kole M, Ilschner S, Kampa B, Williams S, Ruben P, Stuart G: Action potential generation requires a high sodium channel density in the axon initial segment. Nat Neurosci 2008, 11:178-264.

29. Yamakawa K: Molecular and cellular basis: insights from experimental models of Dravet syndrome. Epilepsia 2011, 52(Suppl 2):70-71.

30. Xu Q, Guo L, Moore H, Waclaw R, Campbell K, Anderson S: Sonic hedgehog signaling confers ventral telencephalic progenitors with distinct cortical interneuron fates. Neuron 2010, 65:328-368.

31. Sinha $\mathrm{S}$, Chen J: Purmorphamine activates the Hedgehog pathway by targeting Smoothened. Nat Chem Biol 2006, 2:29-59.

32. Mukhopadhyay A, McGuire T, Peng C-Y, Kessler J: Differential effects of BMP signaling on parvalbumin and somatostatin interneuron differentiation. Development 2009, 136:2633-2675.

33. Xu Q, Tam M, Anderson S: Fate mapping Nkx2.1-lineage cells in the mouse telencephalon. J Comp Neurol 2008, 506:16-45.

34. Xu Q, Cobos I, De La Cruz E, Rubenstein J, Anderson S: Origins of cortical interneuron subtypes. J Neurosci 2004, 24:2612-2634.

35. Xu Q, Wonders $C$, Anderson S: Sonic hedgehog maintains the identity of cortical interneuron progenitors in the ventral telencephalon. Development 2005, 132:4987-5085.

36. Gulacsi A, Anderson SA: Shh maintains Nkx2.1 in the MGE by a Gli3-independent mechanism. Cereb Cortex 2006, 16(Suppl 1):i89-i95.

37. Nakayama T, Ogiwara I, Ito K, Kaneda M, Mazaki E, Osaka H, Ohtani H, Inoue Y, Fujiwara T, Uematsu M, et al: Deletions of SCN1A 5' genomic region with promoter activity in Dravet syndrome. Hum Mutat 2010, 31:820-829.

38. Kalume F, Yu F, Westenbroek R, Scheuer T, Catterall W: Reduced sodium current in Purkinje neurons from $\mathrm{Na}_{\mathrm{v}} 1.1$ mutant mice: implications for ataxia in severe myoclonic epilepsy in infancy. J Neurosci 2007, 27:11065-11139.

39. Duflocq A, Le Bras B, Bullier E, Couraud F, Davenne M: $\mathrm{Na}_{\mathbf{v}} 1.1$ is predominantly expressed in nodes of Ranvier and axon initial segments. Mol Cell Neurosci 2008, 39:180-272.

40. Vacher H, Mohapatra D, Trimmer J: Localization and targeting of voltagedependent ion channels in mammalian central neurons. Physiol Rev 2008, 88:1407-1447.

41. Mashimo T, Ohmori I, Ouchida M, Ohno Y, Tsurumi T, Miki T, Wakamori M, Ishihara S, Yoshida T, Takizawa A, et al: A missense mutation of the gene encoding voltage-dependent sodium channel $\left(\mathrm{Na}_{\mathrm{v}} \mathrm{1} 1 \mathrm{1}\right)$ confers susceptibility to febrile seizures in rats. J Neurosci 2010, 30:5744-5797.

42. Westenbroek R, Merrick D, Catterall W: Differential subcellular localization of the Rl and $\mathrm{Rll} \mathrm{Na}^{+}$channel subtypes in central neurons. Neuron 1989 3:695-1399.

43. Wenze W, Sachio T, Yoshie S, Masayuki I, Xiuyu S, Su-Kyeong H, Kazuki N, Morishige T, Shinichi H: The developmental changes of $\mathrm{Na}_{\mathrm{v}} 1.1$ and $\mathrm{Na}_{\mathrm{v}} 1.2$ expression in the human hippocampus and temporal lobe. Brain Res 2011, 1389:61-70.

44. Trimmer JS, Rhodes KJ: Localization of voltage-gated ion channels in mammalian brain. Annu Rev Physiol 2004, 66:477-996.

45. Amoh Y, Li L, Katsuoka K, Penman S, Hoffman RM: Multipotent nestinpositive, keratin-negative hair-follicle bulge stem cells can form neurons. Proc Natl Acad Sci USA 2005, 102:5530-5534.

46. Amoh Y, Kanoh M, Niiyama S, Hamada Y, Kawahara K, Sato Y, Hoffman RM, Katsuoka K: Human hair follicle pluripotent stem (hfPS) cells promote regeneration of peripheral-nerve injury: an advantageous alternative to ES and iPS cells. J Cell Biochem 2009, 107:1016-1020.

47. Ohta S, Imaizumi Y, Okada Y, Akamatsu W, Kuwahara R, Ohyama M, Amagai M, Matsuzaki Y, Yamanaka S, Okano H, Kawakami Y: Generation of human melanocytes from induced pluripotent stem cells. PLoS One 2011, 6:e16182.

48. Okada Y, Matsumoto A, Shimazaki T, Enoki R, Koizumi A, Ishii S, Itoyama $Y$, Sobue G, Okano H: Spatiotemporal recapitulation of central nervous system development by murine embryonic stem cell-derived neural stem/progenitor cells. Stem Cells 2008, 26:3086-3098.

49. Nori S, Okada Y, Yasuda A, Tsuji O, Takahashi Y, Kobayashi Y, Fujiyoshi K, Koike M, Uchiyama Y, Ikeda E, et al: Grafted human-induced pluripotent stem-cell-derived neurospheres promote motor functional recovery after spinal cord injury in mice. Proc Natl Acad Sci USA 2011, 108:16825-16855.

50. Martin M, Tang B, Ta N, Escayg A: Characterization of 5' untranslated regions of the voltage-gated sodium channels SCN1A, SCN2A, and SCN3A and identification of cis-conserved noncoding sequences. Genomics 2007, 90:225-260.

doi:10.1186/1756-6606-6-19

Cite this article as: Higurashi et al: A human Dravet syndrome model from patient induced pluripotent stem cells. Molecular Brain 2013 6:19.

\section{Submit your next manuscript to BioMed Central and take full advantage of:}

- Convenient online submission

- Thorough peer review

- No space constraints or color figure charges

- Immediate publication on acceptance

- Inclusion in PubMed, CAS, Scopus and Google Scholar

- Research which is freely available for redistribution 